\title{
Rewarding Actions of Phencyclidine and Related Drugs in Nucleus Accumbens Shell and Frontal Cortex
}

\author{
William A. Carlezon, Jr., and Roy A. Wise \\ Center for Studies in Behavioral Neurobiology, Department of Psychology, Concordia University, Montréal, Québec, \\ Canada H3G $1 \mathrm{M} 8$
}

\begin{abstract}
Rats learned to lever-press when such behavior was reinforced by microinjections of phencyclidine (PCP) directly into the ventromedial (shell) region of nucleus accumbens, indicating that the drug has direct rewarding actions in that region. Separate groups of rats learned to lever-press when reinforced with microinjections of dizocilpine (MK-801) or 3-(( \pm$) 2-$ carboxypiperazin-4yl)propyl-1-phosphate (CPP), drugs known to block NMDA receptor function but not dopamine uptake, into the same region. Each drug was ineffective or markedly less effective when injected at a slightly more dorsal and lateral site in the core of nucleus accumbens. Self-administration of PCP, MK-801, or CPP directly into nucleus accumbens was not altered by co-infusion of a dose of the dopamine antagonist sulpiride that effectively blocked intracranial self-administration of the dopamine uptake inhibitor nomifensine, suggesting that the rewarding actions of the NMDA receptor antagonists are
\end{abstract}

Phencyclidine (PCP) is self-administered by humans (Crider, 1986) and rhesus monkeys (Balster and Woolverton, 1980). The rewarding properties of $\mathrm{PCP}$, however, have been difficult to demonstrate in rodents. [Rcwarding drug injections have several consequences. They establish and "reinforce" learned stimulus associations (Pavlov, 1928), they "stamp in" (Thorndike, 1898) or "reinforce" (Skinner, 1933; Thorndike, 1933) stimulus-response associations and "instrumental" or "operant" response habits, and they "prime" or energize subsequent responding (Wetzel, 1963; Pickens and Harris, 1968). The term "reward" is used here to reflect the sum of the proactive (priming) and retruactive (reinforcing) effects of the injections (Wise, 1989).] Rats do not selfadminister PCP as reliably as they do opiates or stimulants (Collins et al., 1984), and they tend to avoid environments that have been associated previously with the administration of the drug (Barr et al., 1985; Iwamoto, 1986). PCP, however, does potentiate the rewarding impact of lateral hypothalamic brain stimulation (Kornetsky and Esposito, 1979; Carlezon and Wise, 1993b), indicating that the drug possesses reward-related properties in rats.

\footnotetext{
Received Sept. 26, 1995; revised Jan. 23, 1996; accepted Jan. 30, 1996.

This work was supported by United States Public Health Service fellowship DA05551 (W.A.C.) and grants from the National Sciences and Engineering Research Council (Canada), Fonds pour la Formation de Chercheurs et l'Aide à la Recherchc (Qućbcc), and the National Institute on Drug $\Lambda$ buse. We thank HoechstRoussel Pharmaceuticals for their gift of nomifensine maleate.

Correspondence should be addressed to Roy A. Wise, Center for Studies in Behavioral Neurobiology, Concordia University, 1455 de Maisonneuve Boulevard West, Montréal, Québec, Canada H3G 1M8.

Dr. Carlezon's present address: Laboratory of Molecular Psychiatry, Connecticut Mental Health Center, Yale University School of Medicine, 34 Park Street, New Haven, CT 06508.

Copyright (c) 1996 Society for Neuroscience $0270-6474 / 96 / 163112-11 \$ 05.00 / 0$
}

not dopamine-dependent. Rats also developed lever-pressing habits when PCP, MK-801, and CPP were each microinjected directly into frontal cortex, a region previously associated with the rewarding actions of cocaine but not nomifensine. Thus nucleus accumbens and frontal cortex are each potential substrates for the rewarding properties of PCP and related drugs, and the ability of these drugs to disrupt NMDA receptor function seems sufficient to account for their rewarding actions. When considered with independent evidence, the present results suggest a model of drug reward within which the critical event is inhibition of medium spiny neurons in nucleus accumbens.

Key words: phencyclidine; MK-801; CPP; NMDA antagonists; self-administration; nucleus accumbens (core, shell); frontal cortex; dopamine; reward
Inasmuch as humans experienced with PCP have reported that the drug possesses powerful dysphoric effects in addition to its euphoric effects (Crider, 1986), it seems likely that the difficulty in dcmonstrating PCP self-administration in rats is attributable to concomitant rewarding and aversive actions.

One way to minimize unwanted side effects of drugs is through the use of direct injections that limit drug dispersion in the brain (Wise and Hoffman, 1992). Rats have been trained to selfadminister intracranial injections of morphine (Bozarth and Wise, 1981), amphetamine (Hoebel et al., 1983), cocaine (Goeders and Smith, 1983; Carlezon et al., 1995), and nomifensine (Carlezon et al., 1995). If the difficulty in demonstrating rewarding actions of $P C P$ in rodents were attributable to mixed rewarding and aversive effects of the drug, and if the circuitry of the two kinds of actions were separated sufficiently in the brain, the rewarding actions of PCP might be demonstrated more readily with central rather than intravenous injections.

It has been suggested that the rewarding effects of several drugs of abuse can be attributed, at least in part, to their ability to interact with the mesolimbic dopamine system and its efferents (Wise and Bozarth, 1987; DiChiara and Imperato, 1988). Systemic administration of PCP increases extracellular concentrations of dopamine in nucleus accumbens (Carboni et al., 1989), as do several other habit-forming drugs (DiChiara and Imperato, 1988; Ng Cheong Ton et al., 1988). PCP causes such increases when infused locally into nucleus accumbens (Hernandez et al., 1988; McCullough and Salamone, 1992) or the frontal cortex (Hondo et al., 1994). PCP has at least two pharmacological properties that may contribute to its ability to elevate dopamine concentrations in terminal regions: it is a dopamine uptake inhibitor (Gerhardt et 
al., 1987), and it increases dopaminergic cell firing (Raja and Guyenet, 1980; Freeman and Bunney, 1984; French, 1986) through its ability to block NMDA receptors (French and Ceci, 1990), probably in dopamine terminal regions (Imperato et al., 1990; Zhang et al., 1992; Hondo et al., 1994).

If the rewarding action of PCP is linked to its ability to elevate extracellular dopamine concentrations, the likely sites of these rewarding actions would be nucleus accumbens or frontal cortex where nomifensine and cocaine (Goeders and Smith, 1983; Carlezon et al., 1995), which share with PCP the ability to inhibit dopamine uptake, are rewarding. The primary purpose of the present study was to determine whether rats would learn to self-administer PCP into either of these regions.

\section{MATERIALS AND METHODS}

Animals and surgery. One hundred seventy-two male Long-Evans rats were used; each rat weighed $350-400 \mathrm{gm}$ at the time of surgery. The rats were housed individually in a room with lights set on a reverse cycle (lights on from 11 P.M. until 9 A.M.) and tested in darkness during their dark phase. Each rat was anesthetized with sodium pentobarbital (65 $\mathrm{mg} / \mathrm{kg}$, i.p.) and given atropine $(0.25 \mathrm{mg} / \mathrm{kg})$ to minimize bronchial secretions. Each of 116 rats was implanted with a unilateral 22 gauge guidc cannula that tcrminatcd $1.1 \mathrm{~mm}$ above the center of the nucleus accumbens $(3.5 \mathrm{~mm}$ anterior to bregma, $2.4 \mathrm{~mm}$ lateral to the midline suture, and $5.9 \mathrm{~mm}$ below dura; the incisor bar was elevated to $5 \mathrm{~mm}$ above the interaural line, and the cannula was angled toward the midline at $10^{\circ}$ from the vertical). Each of 24 other rats was implanted with a guide cannula that terminated $2.1 \mathrm{~mm}$ above nucleus accumbens $(4.9 \mathrm{~mm}$ below dura). Each of the remaining 32 rats was implanted with unilateral 22 gauge guide cannula that terminated $1.1 \mathrm{~mm}$ above the rat analog of the medial prefrontal cortex $(4.1 \mathrm{~mm}$ anterior to bregma, $0.8 \mathrm{~mm}$ lateral to the midline suture, and $1.9 \mathrm{~mm}$ below dura). After the guide cannula was secured to the skull with stainless steel screws and acrylic dental cement, a stainless steel blocker ( 28 gauge) extending $1.1 \mathrm{~mm}$ beyond the tip of the guide cannula was fixed in place; the blocker was removed only during testing.

Diug and vehicle solutions. The drugs used were PCP hydrochloride (National Institute on Drug Abuse, Bethesda, MD), dizocilpine (MK801), 3-(( \pm$)$ 2-carboxypiperazin-4yl)propyl-1-phosphonate (CPP) (Research Biochemicals Inc., Natick, MA), and nomifensine maleate (Hoechst-Roussel Pharmaceuticals, Somerville, NJ). Each drug was dissolved in an artificial extracellular fluid vehicle composed of a $2.0 \mathrm{~mm}$ Sorenson's phosphate buffer that contains $145 \mathrm{mM} \mathrm{Na}^{+}, 2.7 \mathrm{mM} \mathrm{K}^{+}, 1.0$ $\mathrm{mM} \mathrm{Mg}^{2+}, 1.2 \mathrm{mM} \mathrm{Ca}^{2+}, 150 \mathrm{mM} \mathrm{Cl}^{-}$, and $0.2 \mathrm{mM}$ ascorbate, $\mathrm{pH} 7.4$ (Moghaddam and Bunney, 1989). The nomifensine solution was vibrated in an ultrasonic cleaning bath until the drug dissolved.

Apparatus. Each rat was tested in a $26 \mathrm{~cm} \times 26 \mathrm{~cm} \times 26 \mathrm{~cm}$ operant chamber equipped with a single response lever mounted on the rear wall, $6 \mathrm{~cm}$ above a grid floor. A white cue light $(2.3 \mathrm{~cm}$ in diameter $)$ was mounted on the wall $9 \mathrm{~cm}$ above the lever, and a wooden block was placed below the lever to prevent the animals from entangling their headgear or wire lead with the lever. Each operant chamber was contained in a sound-attenuating box illuminated with a $\operatorname{dim}(15 \mathrm{~W})$ red light.

Drug or vehicle solution was delivered by an electrolytic microinfusion transducer (EMIT) drug-delivery system (Criswell, 1977) attached to an injection cannula and mounted on the head assembly of the animal (Bozarth and Wise, 1980). Depression of the response lever resulted in the passage of a $200 \mu \mathrm{A}$ constant current (Mundl, 1981) across platinum electrodes in the drug reservoir; application of such current for $5 \mathrm{sec}$ generated sufficient gas from the aqueous solution in the reservoir to displace $120 \mathrm{nl}$ of solution from the tip of the injection cannula. A small quiescent current $(10 \mu \Lambda)$ prevented the gas from redissolving into the aqueous solution but was not sufficient to displace more solution. Leverpresses that occurred during each $5 \mathrm{sec}$ infusion did not result in the delivery of additional drug but were counted by a microprocessor nonetheless.

General procedure. The rats were allowed to recover from surgery for at least $10 \mathrm{~d}$ and were handled on several occasions during this recovery time. In our experience, such handling ensures greater exploratory activity, hence more initial lever-presses, when testing begins. Nine of the 116 rats with guide cannulae terminating $1.1 \mathrm{~mm}$ above nucleus accumbens were used in the initial dose-determination studies (see below), and data from these animals were not included in subsequent analyses. Of the remaining 107 animals with nucleus accumbens placements, 56 were used to characterize the intracranial self-administration of the NMDA receptor antagonists, and the remaining 51 were used in a separate experiment to determine whether the self-administration was dopamine-dependent (see below). Twenty-four animals with placements above nucleus accumbens ("dorsal controls") were used to assess the rewarding effects of drug efflux up the shaft of the cannula; this is the most significant direction of drug diffusion in central injection studies (Wise and Hoffman, 1992). Thirty-two animals with frontal cortex placements were used to determine whether drug concentrations that effectively established and maintained lever-pressing when administered into nucleus accumbens would also be sufficient to reinforce responding when administered into the frontal cortex.

Self-administration of PCP into nucleus accumbens studies. To characterize intracranial self-administration of PCP, MK-801, and CPP into nucleus accumbens, 16 animals with cannula placements $1.1 \mathrm{~mm}$ above nucleus accumbens were assigned to each drug condition; a fourth group of eight animals was assigned to the vehicle condition. Within each drug condition, the 16 animals were divided further into two groups of eight animals. Each animal in the first group (the "test" group) received response-contingent microinjections of drug (that is, they "earned" an injection each time they pressed the lever), whereas each animal in the second group served as a "yoked" partner for an animal in the first group (receiving "unearned" injections each time their yoked partner leverpressed). The animals in the vehicle condition reccivcd responsecontingent microinjections of vehicle. The 24 animals with guide cannulae terminating $2.1 \mathrm{~mm}$ above nucleus accumbens (dorsal controls) were divided into three groups of eight animals each (one group per drug) and were allowed to earn response-contingent drug injections $1 \mathrm{~mm}$ dorsal to those given in the primary groups.

Before each test session, the reservoir of each EMIT unit was filled with the appropriate drug or vehicle solution, and the injector cannula was inserted through the guide cannula and screwed into place. Each animal was then placed in an operant chamber. For those animals tested under response-contingent conditions (animals in the test, vehicle, and dorsal groups), each depression of the lever resulted in illumination of the white cue light and delivery of $120 \mathrm{nl}$ drug or vehicle solution. Each yoked animal received a similar injection and had its cue light illuminated whenever its yoked partner earned an injection; lever-presses by yoked animals were recorded but had no scheduled consequences.

All animals were first tested in eight $3 \mathrm{hr}$ sessions scheduled on alternate days. During a ninth session, vehicle was substituted for drug. Each drug solution was made available again at its original concentration for 2 additional days (animals in the vehicle group received vehicle on all 11 test sessions). The animals did not receive priming injections of drug, nor was their behavior "shaped" by rewarding successive approximations of the required response.

Dose determination studies. To identify the relevant dose ranges for each drug, three animals were tested initially with varying drug concentrations. PCP was tested in each animal at concentrations of 1.2,3.6, and $12 \mathrm{nmol} / 120 \mathrm{nl}$ infusion. These concentrations were tested because they have been reported to increase extracellular dopamine levels when applied locally to the nuclcus accumbens (Hernandez et al., 1988; McCullough and Salamone, 1992). MK-801 was tested in each animal at concentrations of $0.12,0.36$, and $1.2 \mathrm{nmol} /$ infusion. Thesc concentrations were tested because the drug is $10-20$ times more potent than PCP in behavioral assays (see Hiramatsu et al., 1989; compare Corbett, 1989, with Carlezon and Wise, 1993a,b). Finally, CPP was tested in each animal at $0.06,0.12$, and $0.24 \mathrm{nmol}$. These concentrations were tested because the drug is 200-500 times more potent than PCP when administered intracranially (Koek and Colpaert, 1990). The animals of each group learned to self-administer their target drug (data not presented); the minimum effective doses of the drugs were $\mathrm{PCP}=12 \mathrm{nmol} / \mathrm{infusion}$, MK-801 $=1.2 \mathrm{nmol} /$ infusion, and CPP $=0.06 \mathrm{nmol} /$ infusion.

Dopamine-dependence studies. Forty-eight of the 51 rats used to characterize the dopamine-dependence of NMDA receptor antagonist selfadministration into nucleus accumbens were divided into four groups of 12 animals each and assigned one of four drugs: the NMDA receptor antagonists $\mathrm{PCP}, \mathrm{MK}-801$, or CPP, or the dopamine uptake inhibitor nomifensine. The remaining three rats were used to determine a dose of sulpiride that would effectively block the rewarding actions of nucleus accumbens nomifensine (see below). All animals were tested under response-contingent conditions: depression of the lever resulted in illu- 


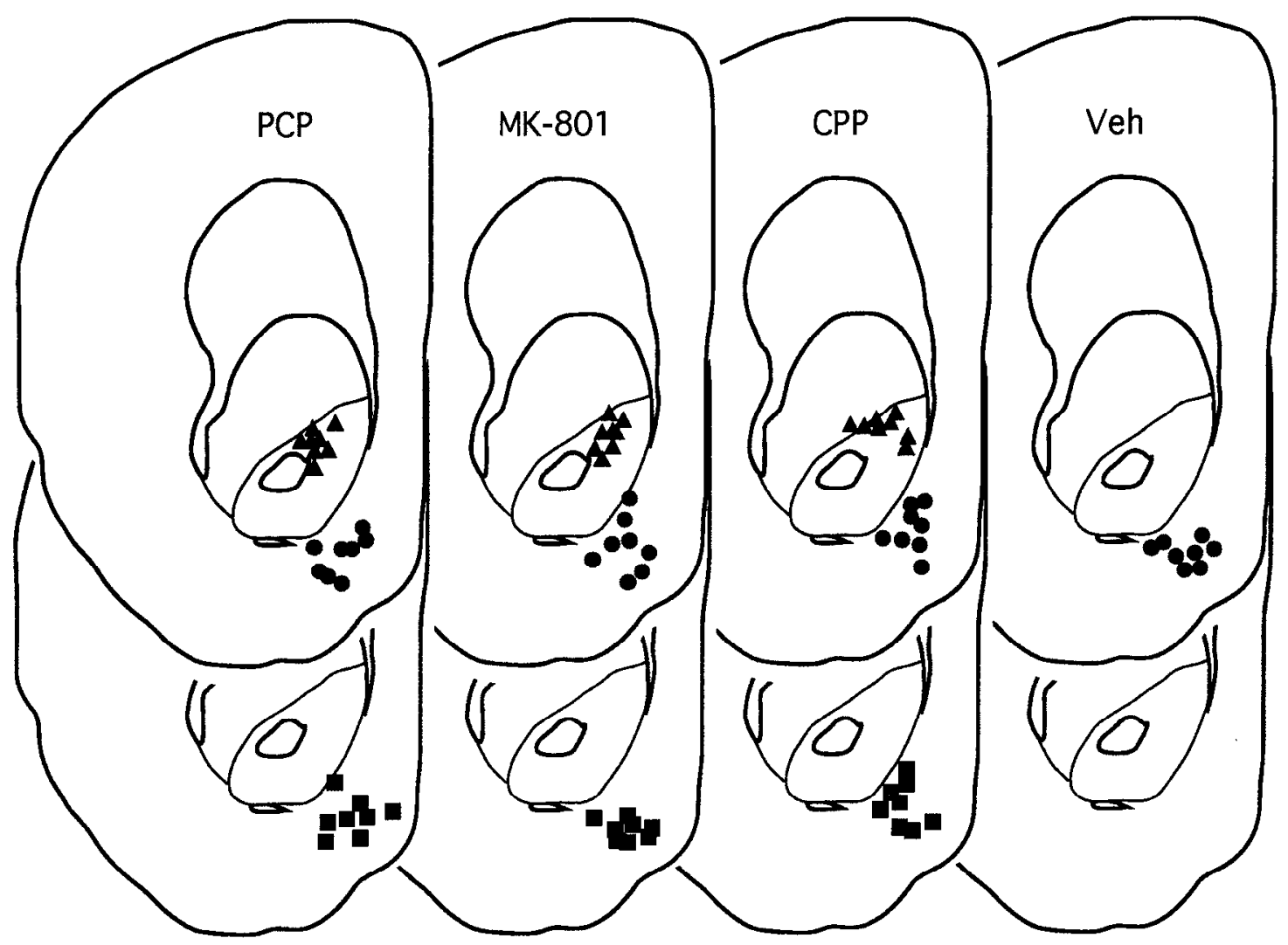

Figure 1. Cannula placements for nucleus accumbens drug injections. The upper sections represent sites of response-contingent injections (circles represent effective sites in the shell region of nucleus accumbens, and triangles represent "dorsal control" sites in the core of nucleus accumbens). The lower sections represent "yoked control" sites. All placements are represented on the same anterior-posterior section (3.4 mm anterior to bregma); actual placements varied between 3.4 and $3.8 \mathrm{~mm}$ anterior to bregma (figure adapted from Pellegrino et al., 1979). Veh, Vehicle.

mination of the white cue light and delivery of $120 \mathrm{nl}$ of the assigned drug solution by the EMIT system.

Each animal was tested with its assigned drug on alternate days until response rate was stable for four consecutive test sessions $(<10 \%$ variability between sessions). During the session after the response stabilization, half of the animals ( $n=6$ per drug) received their training drug co-infused with sulpiride (120 pmol per infusion; see below), whereas the remaining animals received vehicle instead of their training drug. Each animal was tested under these conditions a total of four times, with 2 retraining days (normal reinforcement) between each of these "substitution" sessions.

After the two sessions of retraining after the fourth substitution test, the trealment conditions were reversed. Thuse animals accustomed to repeated testing with vehicle were tested with their training drug combined with sulpiride, and those animals accustomed to repeated testing with the combination of their training drug and sulpiride were tested with vehicle.

Sulpiride dose determination studies. Preliminary studies to determine the minimum dose of sulpiride required to block the rewarding properties of intra-accumbens nomifensine were carried out in three animals trained previnusly to self-administer nomifensine $(1.7 \mathrm{nmol}$ per infusion; Carlezon et al., 1995). Each animal was tested during three consecutive sessions with nomifensine mixed (in counterbalanced order) with one of the following three doses of sulpiride: $360 \mathrm{pmol} / 120 \mathrm{nl}$ (Goeders and Smith, 1986), $120 \mathrm{pmol} / 120 \mathrm{nl}$, or $40 \mathrm{pmol} / 120 \mathrm{nl}$. The two highest doses of sulpiride were comparably effective at decreasing responding reinforced with nomifensine, whereas there was no significant effect of the lowest dose on lever-pressing rates (data not presented). Accordingly, the dose of sulpiride selected to test in substitution-naive animals was 120 $\mathrm{pmol} / 120 \mathrm{nl}$.

Frontal cortex studies. The 32 animals were divided into four groups of eight animals. One group was assigned to each of the three NMDA receptor antagonists, and a fourth group was assigned to the vehicle condition. These animals were tested under the response-contingent conditions and at the drug concentrations that effectively established and maintained self-administration in the case of nucleus accumbens injections.

Histology. After the completion of experiments, the brain of each animal was removed, frozen, and sliced in $40 \mu \mathrm{m}$ coronal sections to determine the location of the tip of its injector.

Statistical analyses. For the nucleus accumbens self-administration studies, data from each drug condition were analyzed separately, and data from the vehicle group were used for comparison in each instance. Within each drug condition, the number of lever-presses per $3 \mathrm{hr}$ session was compared among the various control groups using a $4 \times 11$ (treatment times sessions) ANOVA with repeated measures. For the dopaminedependence studies, group differences between the mean number of daily lever-presses during the final $4 \mathrm{~d}$ of baseline training, the $4 \mathrm{~d}$ of substitution, and the reversal day were compared for each drug using a $2 \times 9$ (substitution type times sessions) ANOVA with repeated measures. For the frontal cortex studies, data from each drug condition were analyzed separately; for each drug, the mean number of daily lever-presses was compared between the drug and vehicle group using a $2 \times 11$ (treatment times sessions) ANOVA with repeated measures.

Any significant main effects revealed in an ANOVA were examined further using simple main effect tests followed by Tukey's protected $t$ tests. Significant interactions revealed in an ANOVA were examined further using Tukey's tests.

\section{RESULTS}

\section{Injection sites}

Although the primary injection site was intended to be in the center of the nucleus accumbens and the dorsal control site was intended to be in the overlying caudate, it was discovered on histological analysis that the primary injection sites were in the ventromedial aspect of the nucleus accumbens (the nucleus ac- 

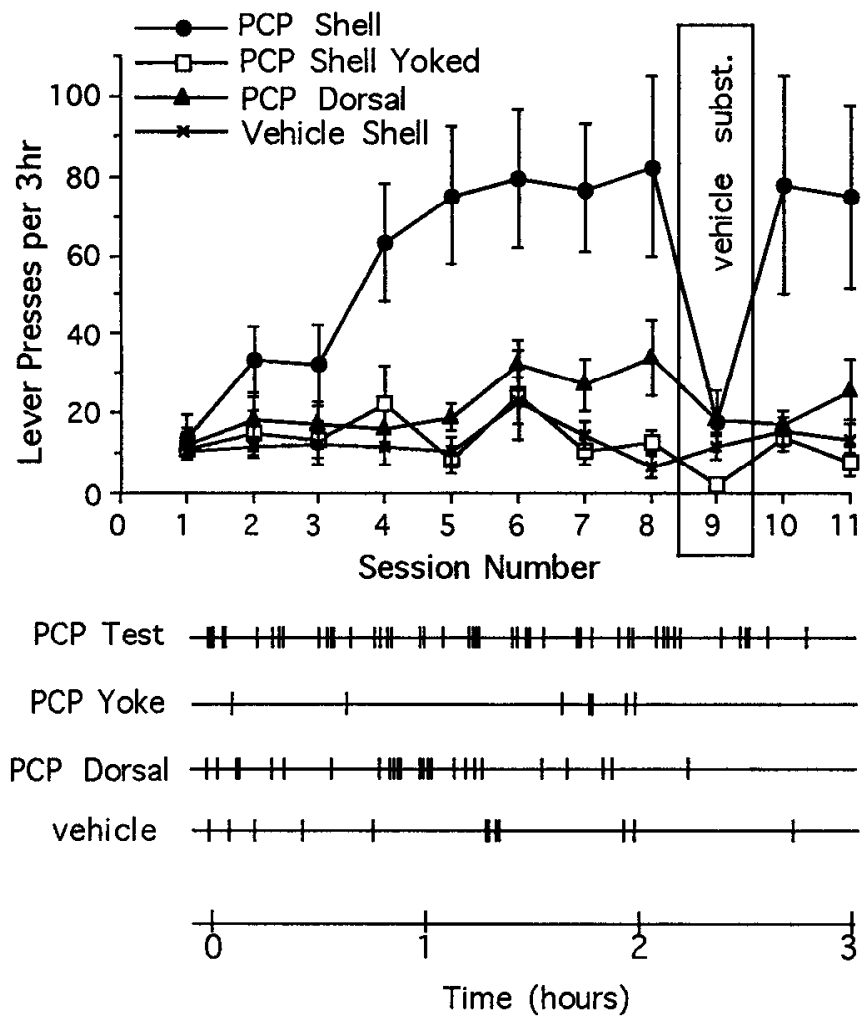

Figure 2. Top, Mean \pm SEM number of lever-presses as a function of session for rats given access to microinjections of PCP or vehicle directly in nucleus accumbens shell and microinjections of PCP dorsal to the shell region, and for rats given noncontingent (yoked) microinjections of PCP directly into the shell. The number of lever-presses increased progressively when rats were given earned PCP into the shell region (interaction: $\left.F_{(30,280)}=2.49 ; p<0.01\right)$; lever-pressing rates were elevated ('lukey's tests) for these animals during sessions $4-8$ and $10-11(p<0.01)$. The lever-pressing rates of animals that received more dorsal injections were elevated during session 8 only $(p<0.05)$. Bottom, Response records during the eighth session for individual animals from each of the four testing conditions. The animal tested under noncontingent (PCP Yoke) conditions received a microinjection of PCP whenever the animal tested under response-contingent ( $P C P$ Test) conditions earned an infusion. Each vertical mark indicates the time of a single lever-press.

cumbens shell) (Fig. 1) and that the dorsal control sites were in the dorsal aspect of the nucleus accumbens (the nucleus accumbens core) (Fig. 1) (Zahm and Brog, 1992). There were no apparent differences in injector tracks between the three drug conditions for either shell or core placements.

\section{Intracranial self-administration of PCP into nucleus accumbens}

Rats readily learned to lever-press when response-contingent (earned) microinjections of PCP (12 nmol/injection) were given into the shell of nucleus accumbens (primary injection site) (Fig. 2, top; the details of the statistical comparisons are given in the figure legends). Progressive increases in lever-pressing were nol reliably observed (1) when similar injections were given in random relation to the behavior of the animal ("yoked injections") or (2) when response-contingent injections of vehicle were given into the same injection site. By the eighth test session, animals that were receiving earned microinjections of $\mathrm{PCP}$ into the shell of the nucleus accumbens reliably lever-pressed at an elevated rate throughout the test session (Fig. 2, bottom), whereas those animals given response-contingent microinjections of vehicle pressed at low rates and at random intervals. A minimal increase in lever-pressing (statistically significant on the eighth day of testing only) was seen when response-contingent injections were given into the core of the nucleus accumbens (at the dorsal control site). Rats given yoked microinjections of PCP also pressed at low rates, but responses often occurred shortly after an infusion. In the case of animals earning microinjections of PCP into the shell region, mean rates of lever-pressing diminished rapidly when vehicle was substituted for PCP during the ninth test session (Fig. 2, top), but elevated rates were reinstated rapidly when the drug was made available again during the final two test sessions. Response rates also decreased when vehicle was substituted for PCP in animals with placements in the core region, but in this case there was not a significant immediate "rebound" when drug reinforcement was reinstated. Response rates were not depressed by vehicle substitution or increased by drug reinstatement in the yoked condition.

The same essential features of intra-accumbens selfadministration were observed when other animals were tested with either the NMDA-receptor channel-blocker MK-801 (Fig. 3) or the competitive NMDA receptor antagonist CPP (Fig. 4). (1) Response-contingent microinjections of MK-801 or CPP into the shell region established lever-pressing habits; (2) these habits were suppressed by vehicle substitution; and (3) the habits were reinstated when drug reinforcement was resumed. Animals given earned microinjections of $\mathrm{MK}-801$ into the core of the nucleus
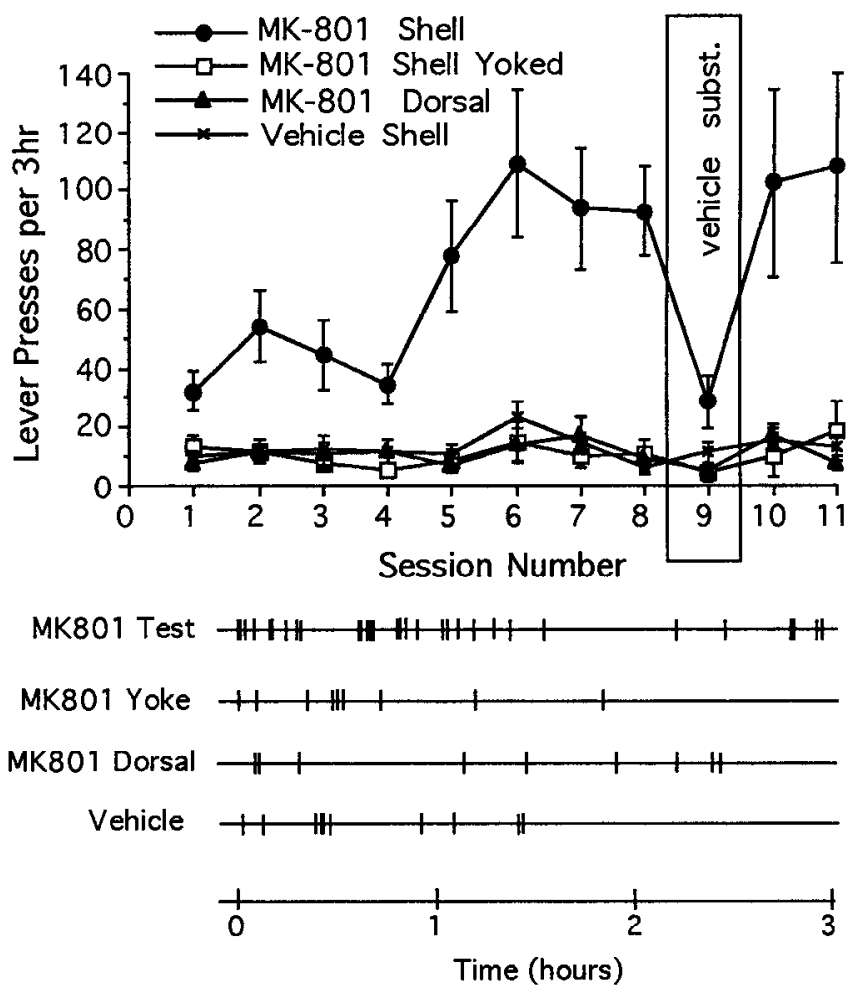

Figure 3. Top, Mean \pm SEM number of lever-presses as a function of session for rats given access to microinjections of MK-801 or vehicle directly into the nucleus accumbens shell and MK-801 dorsal to the shell region, and for rats given noncontingent (yoked) microinjections of MK801 into the shell region. The number of daily lever-presses increased progressively only when rats were given earned MK-801 into the nucleus accumbens (interaction: $F_{(30,280)}=2.58 ; p<0.01$ ); lever-pressing rates were elevated (Tukey's tests) for these animals during sessions 2-3, 5-8, and 10-11 $(p<0.01)$. Bottom, Response records during the eighth session for individual animals from each of the four testing conditions. 
accumbens did not acquire a self-administration habit, but animals given microinjections of CPP did.

\section{Dopamine-dependence of intra-accumbens drug self-administration}

Rats lever-pressing for nomifensine into the shell of the nucleus accumbens required $12.3( \pm 1.0)$ sessions of testing with normal reinforcement before their responding was considered stable enough $(<10 \%$ variability) for substitution testing (see Carlezon et al., 1995, for previous characterization of self-administration of nomifensine directly into the shell region of nucleus accumbens). During the final $4 \mathrm{~d}$ of the stabilization period (baseline), there were no statistically significant differences in response rates of animals assigned to receive substitution testing with vehicle and those assigned to receive nomifensine plus sulpiride (Fig. 5, top). Response counts remained normal during the first substitution test regardless of whethar the animals received vehicle or the combination of nomifensine plus sulpiride. Normal response counts, however, were not maintained when animals were given repcated testing cither with vehicle substituted for nomifensinc or with the combination of nomifensine plus sulpiride (Fig. 5, top). Rather, responding across the four repeated test sessions de-
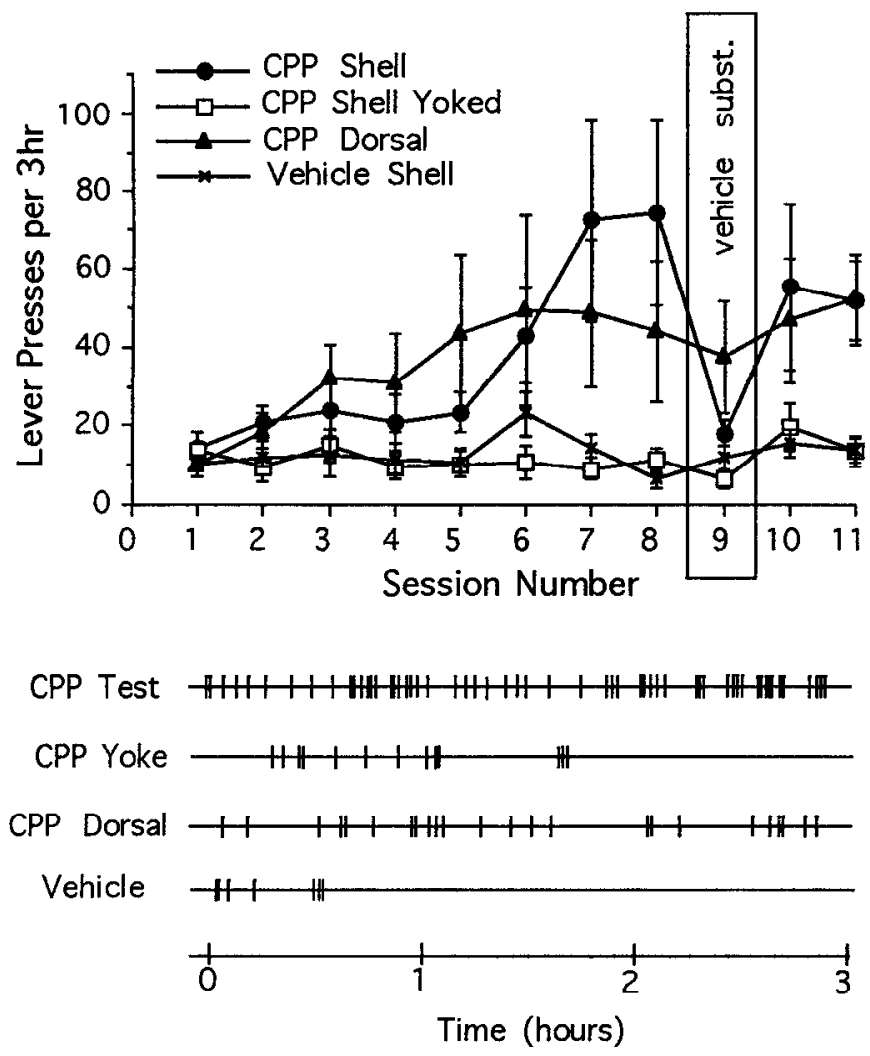

Figure 4. Top, Mean \pm SEM number of lever-presses as a function of session for rats given access to microinjections of CPP or vehicle directly in nucleus accumbens shell and microinjections of CPP dorsal to the shell region, and for rats given noncontingent (yoked) microinjections of CPP into the shell region. The number of daily lever-presses increased progressively whether rats were given earned CPP into the shell region or into the dorsal site (interaction: $F_{(30,280)}=2.08 ; p<0.01$ ). Lever-pressing rates were elevated (Tukey's tests) for animals receiving CPP into the shell region during sessions $7-8$ and $10-11(p<0.01)$; rates were also elevated for animals receiving CPP into the more dorsal region during sessions 5-6 $(p<0.05), 7-8$, and 10-11 $(p<0.01)$. Bottom, Response records during the eighth session for individual animals from each of the four testing conditions.
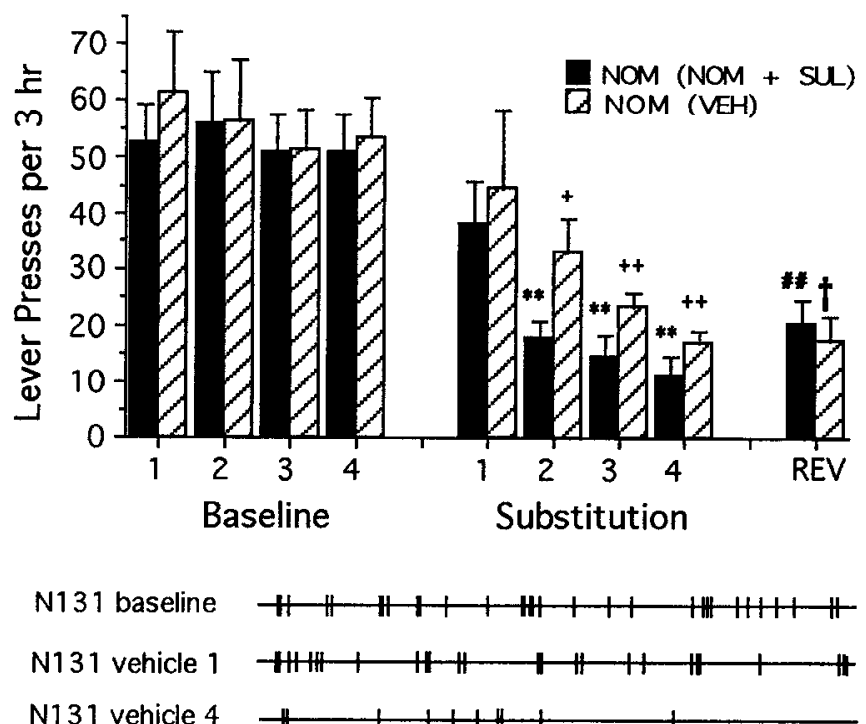

N133 baseline

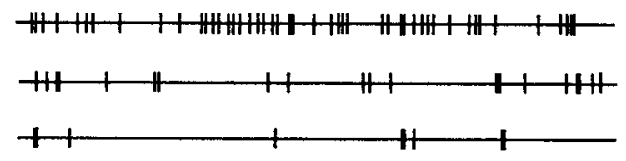

NT33 sulpiride 4

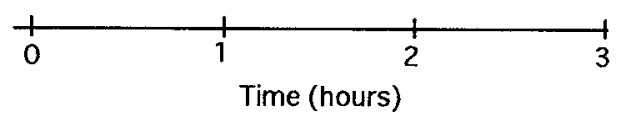

Figure 5. Top, Mean \pm SEM rates of lever-pressing per 3 hr test session under normal drug reinforcement conditions (Baseline) and after repeated substitution of nomifensine either with vehicle [NOM (VEH), striped bars] or with the nomifensine plus sulpiride (NOM $+S U L)$ combination (solid bars). All animals had received only response-contingent nomifensine before the first substitution test. Normal (baseline day 1) rates of leverpressing decreased with repeated substitution testing (main effect of sessions: $\left.F_{(8,80)}=18.9 ; p<0.01\right)$ regardless of whether the animals received vehicle or the nomifensine plus sulpiride conbination. During the reversal session ( $R E V$ ), the animals accustomed to repeated substitution testing with vehicle received the nomifensine plus sulpiride combination for the first time, and their response rates were significantly (lukey's tests) lower than those of animals that were tested with the nomifensine plus sulpiride combination during the first substitution day. Likewise, when the animals accustomed to repeated substitution testing with the nomifensine plus sulpiride combination received vehicle for the first time during the reversal test, their response rates were significantly lower than those of animals tested with vehicle during the first substitution day. Significant differences are indicated as follows: ${ }^{* *} p<0.01$ versus nomifensine (plus sulpiride), baseline session $4 ;{ }^{+} p<0.05,{ }^{++} p<0.01$ versus nomifensine (vehicle), baseline session $4 ;{ }^{\#} p<0.01$ versus nomifensine (vehicle), substitution session $1 ; \uparrow p<0.05$ versus nomifensine (plus sulpiride), substitution session 1. Bottom, Response records for representative animals first trained to lever press for response-contingent nomifensine, and then tested repeatedly with either vehicle (VEH) or the combination of nomifensine plus sulpiride (NOM + SUL). The first three records are from a representative animal (N131) tested repeatedly with vehicle; the first record represents baseline lever-pressing rates for response contingent nomifensine, whereas the second and the third records represent lever-pressing rates during the first and fourth substitution with vehicle. The last three records are from a representative animal (N133) tested repeatedly with the combination of nomifensine plus sulpiride; the fourth record represents baseline response lever-pressing rates for response-contingent nomifensinc, whereas the fifth and sixth records represent lever-pressing rates during the first and fourth substitution with the combination of nomifensine plus sulpiride. 
creased progressively in a pattern similar to that reported previously in the case of food reward and a dopamine antagonist (Wise et al., 1978). Although normal mean response counts were maintained during the first substitution session, responses in each condition tended to be bunched at the beginning of the session (Fig. 5, bottom). When animals accustomed to repeated substitution testing with vehicle were tested with the combination of nomifensine plus sulpiride for the first time ("reversal test"), their rates of lever-pressing remained low: significantly lower than those of animals tested with the combination during the first substitution test (without experience in the vehicle-substitution test). Likewise, when animals accustomed to repeated testing with the combination of nomifensine plus sulpiride were tested with vehicle for the first time during the reversal test, their rates of rcsponding similarly remained low: significantly lower than those of animals tested with vehicle during the first substitution test. These findings established that $120 \mathrm{pmol} /$ injection of sulpiride was a sufficient dose to block the rewarding impact of a dopamine uptake inhibitor not sharing the action of PCP at NMDA receptors.

Rats lever-pressing for PCP into the shell of the nucleus accumbens required $9.9(10.7)$ sessions of testing with normal reinforcement before meeting the stability criterion for substitution testing. Response counts remained normal throughout the substitution testing when animals received the combination of PCP plus sulpiride; however, response rates dropped significantly when the same animals were tested subsequently under conditions of vehicle substitution (Fig. 6, top). Responding was depressed in animals tested four times with vehicle substitution, but rebounded to normal when these same animals were tested with the combination of PCP plus sulpiride (Fig. 6, top). In the case of PCP plus sulpiride, responding was bunched toward the early portions of the session, whereas in the case of normally reinforced responding and testing with the combination of PCP plus sulpiride, responding tended to be distributed more evenly throughout the session (Fig. 6, bottom).

As was found in animals trained to lever-press for intraaccumbens PCP, coadministration of sulpiride failed to alter selfadministration of MK-801 (Fig. 7) (10.1 $\pm 1.2 \mathrm{~d}$ to stable responding) or of CPP (Fig. 8) (10.8 $\pm 1.1 \mathrm{~d}$ to stable responding), nor was responding affected significantly by previous experience on the day when substitution treatments were reversed.

The injector tips of all animals were located within the shell region of the nucleus accumbens (Fig. 1). The variation between injector tracks among the various groups of animals was minimal. There were no systemic differences between groups, nor were there obvious differences between the placements of these animals and those of the animals in the self-administration acquisition study.

\section{Intracranial self-administration of PCP into frontal cortex}

Each of the NMDA receptor antagonists were reinforcing in the frontal cortex at the same concentrations that were effective in the shell of the nucleus accumbens: rats learned to lever-press when given response-contingent microinjections of PCP (12 nmol/injection) (Fig. 9A), MK-801 (1.2 nmol/injection) (Fig. 9B), or CPP $(0.06 \mathrm{nmol} /$ injection) (Fig. $9 C)$ directly into the frontal cortex. For all animals, the injector tips were located within the frontal cortex, medial to the corpus collosum, lateral to the midline, and slightly deeper than the most dorsal aspect of the corpus collosum (Pellegrino et al., 1979) (Fig. 10). The variation between injector
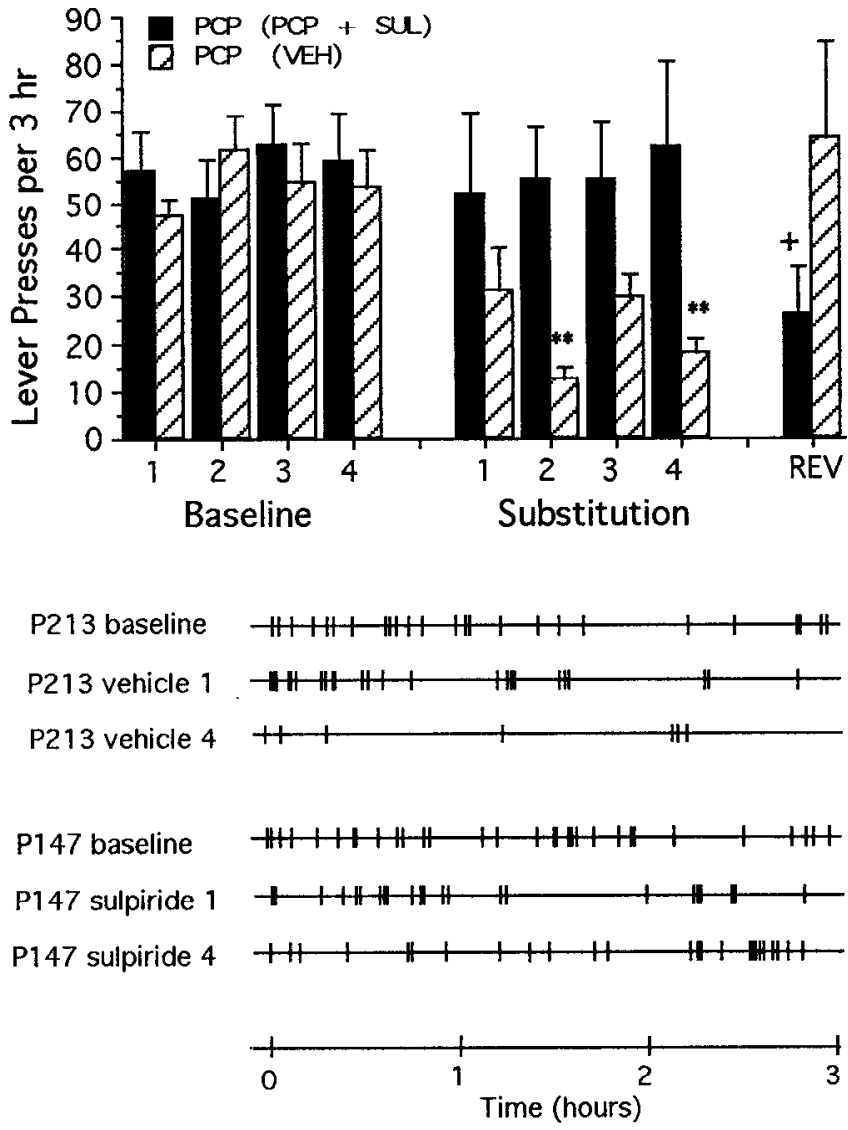

Figure 6. Top, Mean \pm SEM rates of lever-pressing per 3 hr test session under normal drug reinforcement conditions (Baseline) and after repeated substitution of PCP either with vehicle $[P C P(V E H)$, striped bars] or with the PCP plus sulpiride combination $(P C P+S U L$, solid bars). Rates of lever-pressing changes according to whether PCP was substituted with vehicle or the PCP plus sulpiride combination (interaction: $F_{(8,80)}-3.92$; $p<0.01$ ). Within-group response rates were lower than those seen on the final day of baseline testing during substitution sessions 2 and 4 when the animals tested repeatedly with vehicle, but the rates did not change when animals were tested repeatedly with the $\mathrm{PCP}$ plus sulpiride combination. During reversal session, the response rates of animals with previous experience with vehicle were not different from baseline, indicating no transfer between the vehicle and PCP plus sulpiride conditions. Significant differences (Tukey's tests) are indicated as follows: ${ }^{*} p<0.01$ versus PCP (vehicle), baseline session $4 ;{ }^{+} p<0.05$ versus PCP (plus sulpiride), baseline session 4. Bottom, Response records for representative animals first trained to lever-press for response-contingent PCP, and then tested repeatedly with either vehicle or the combination of PCP plus sulpiride. The first three records are from a representative animal (P213) tested repcatedly with vehiclc; the first rccord represents baseline lever-pressing rates for response contingent $\mathrm{PCP}$, whereas the second and third records represent lever-pressing rates during the first and fourth substitution with vehicle. The last three records are from a representative animal (P147) tested repeatedly with the combination of PCP plus sulpiride; the fourth record represents baseline response lever-pressing rates for responsecontingent PCP, whereas the fifth and sixth records represent leverpressing rates during the first and fourth substitution with the combination of PCP plus sulpiride.

tracks among the various groups of animals was minimal, and there were no systemic differences between groups.

\section{DISCUSSION}

The present experiments identify the shell region of nucleus accumbens and the frontal cortex, two regions that receive dopaminergic projections from the ventral tegmental area of the 

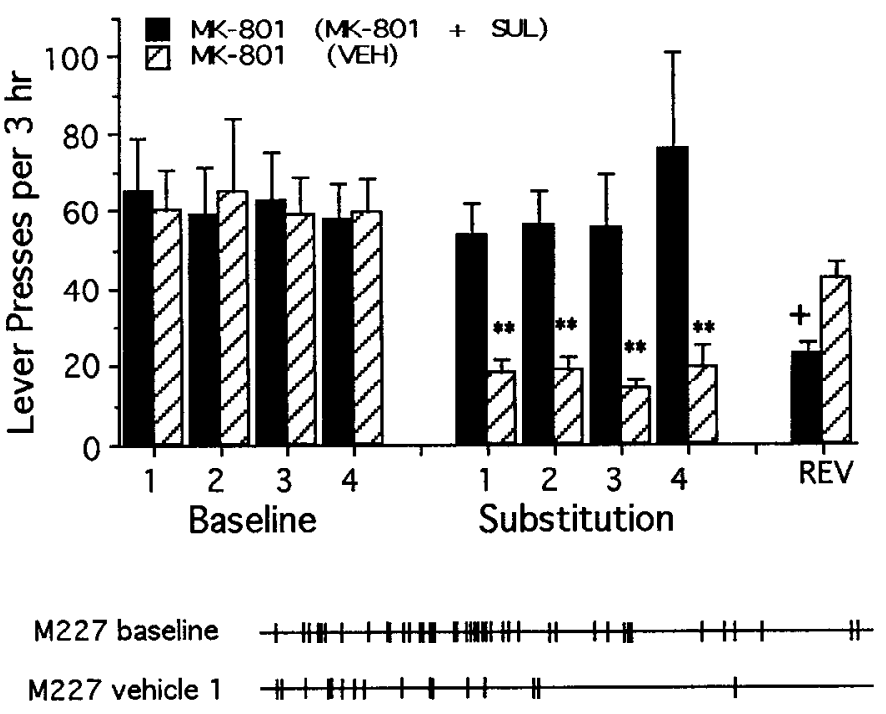

M227 vehicle 4

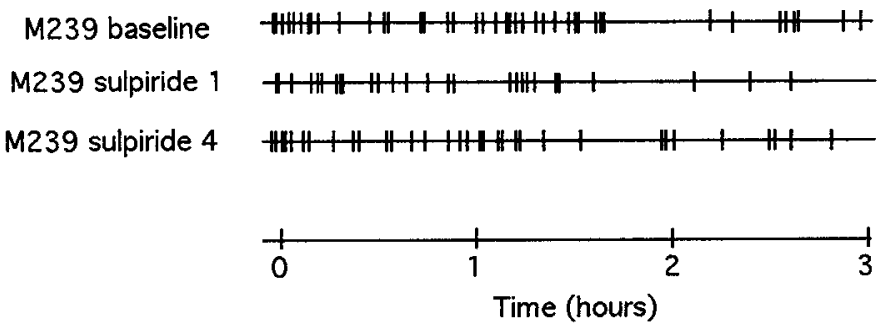

Figure 7. Top, Mean \pm SEM rates of lever-pressing per $3 \mathrm{hr}$ test session under normal drug reinforcement conditions (Baseline) and after repeated substitution of MK- 801 with either vehicle $[M K-801$ (VEH), striped bars] or with the MK-801 plus sulpiride combination $(M K-801+S U L$, solid bars). All animals had received only response-contingent MK-801 before the first substitution test. Rates of lever-pressing changes according to whether MK-801 was substituted with vehicle or the MK-801 plus sulpiride combination (interaction: $F_{(8,80)}=3.83 ; p<0.01$ ). Within-group response rates were lower than those seen on the final day of baseline testing during all substitution sessions when the animals were tested repeatedly with vehicle, but the rates did not change when animals were tested repeatedly with the MK-801 plus sulpiride combination. During reversal session, the response rates of animals with previous experience with vehicle were not different from baseline, indicating no transfer between the vehicle and PCP plus sulpiride conditions. Significant differences (Tukey's tests) are indicated as follows: ** $p<0.01$ versus MK-801 (vehicle), baseline session $4 ;{ }^{+} p<0.05$ versus MK-801 (plus sulpiride), baseline session 4. Bottom, Response records for representative animals first trained to lever-press for response-contingent $\mathrm{MK}-801$, and then tested repeatedly with either vehicle or the combination of MK-801 plus sulpiride. The first three records are from a representative animal (M227) tested repeatedly with vehicle; the first record represents bascline lever-pressing rates for responsecontingent MK-801, whereas the second and third records represent lever-pressing rates during the first and fourth substitution with vehicle. The last three records are from a representative animal (M239) tested repeatedly with the combination of MK-801 plus sulpiride; the fourth record represents baseline response lever-pressing rates for responsecontingent MK-801, whereas the fifth and sixth records represent leverpressing rates during the first and fourth substitution with the combination of MK-801 plus sulpiride.

midbrain, as potential trigger zones for the habit-forming effects of systemically administered PCP. These data add to previous evidence implicating circuitry associated with the mesocorticolimbic dopamine system in the rewarding effects of drugs with psychomotor-stimulant properties (Wise, 1982; Wise and Bozarth,

1987; Koob and Bloom, 1988). The present data, however, do not establish that the rewarding actions of PCP as self-administered by humans involve direct actions on dopaminergic neurons or, for that matter, involve the identified sites of potential action. First, it may be that systemically administered doses of PCP activate reward-related circuitry in other parts of the brain more effec-
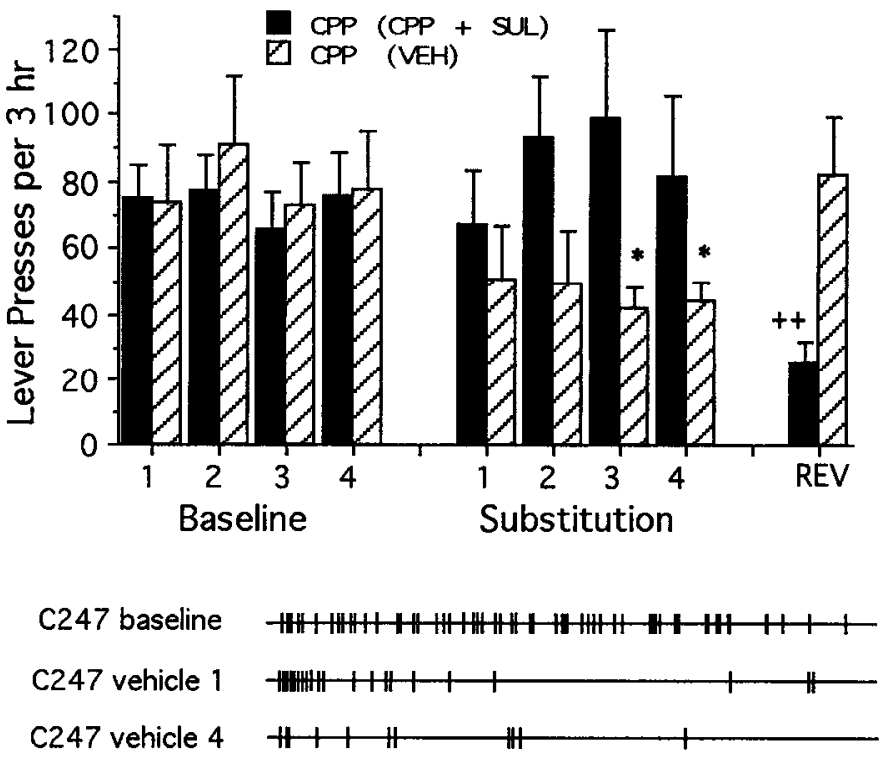

C244 baseline

C244 sulpiride 1

C244 sulpiride 4

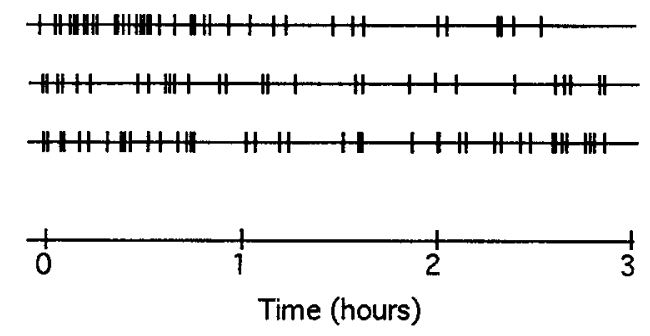

Figure 8. Top, Mean \pm SEM rates of lever-pressing per $3 \mathrm{hr}$ test session under normal drug reinforcement conditions (Baseline) and after repeated substitution of CPP with either vehicle [CPP (VEH), striped bars] or with the CPP plus sulpiride combination $(C P P+S U L$, solid bars). All animals had received only response-contingent CPP before the first substitution test. Rates of lever-pressing changes according to whether CPP was substituted with vehicle or the CPP plus sulpiride combination $\left(F_{(8,80)}=\right.$ $4.82 ; p<0.001$ ). Within-group response rates were lower than those seen on the final day of baseline testing during substitution sessions 3 and 4 when the animals were tested repeatedly with vehicle, but the rates did not change when animals were tested repeatedly with the CPP plus sulpiride combination. During reversal session, the response rates of animals with previous experience with vehicle were not different from baseline, indicating no transfer between the vehicle and CPP plus sulpiride conditions. Significant differences (Tukey's tests) are indicated as follows: ${ }^{*} p<0.05$ versus CPP (vehicle), baseline session $4 ;^{++} p<0.01$ versus CPP (plus sulpiride), baseline session 4. Bottom, Response records for representative animals first trained to lever press for response-contingent $\mathrm{CPP}$, and then tested repeatedly with either vehicle or the combination of CPP plus sulpiride. The first three records are from a representative animal (C247) tested repeatedly with vehicle; the first record represents baseline leverpressing rates for response contingent CPP, whereas the second and the third records represent lever-pressing rates during the first and fourth substitution with vehicle. The last three records are from a representative animal (C244) tested repeatedly with the combination of CPP plus sulpiride; the fourth record represents baseline response lever-pressing rates for response-contingent CPP, whereas the fifth and sixth records represent lever-pressing rates during the first and fourth substitution with the combination of CPP plus sulpiride. 

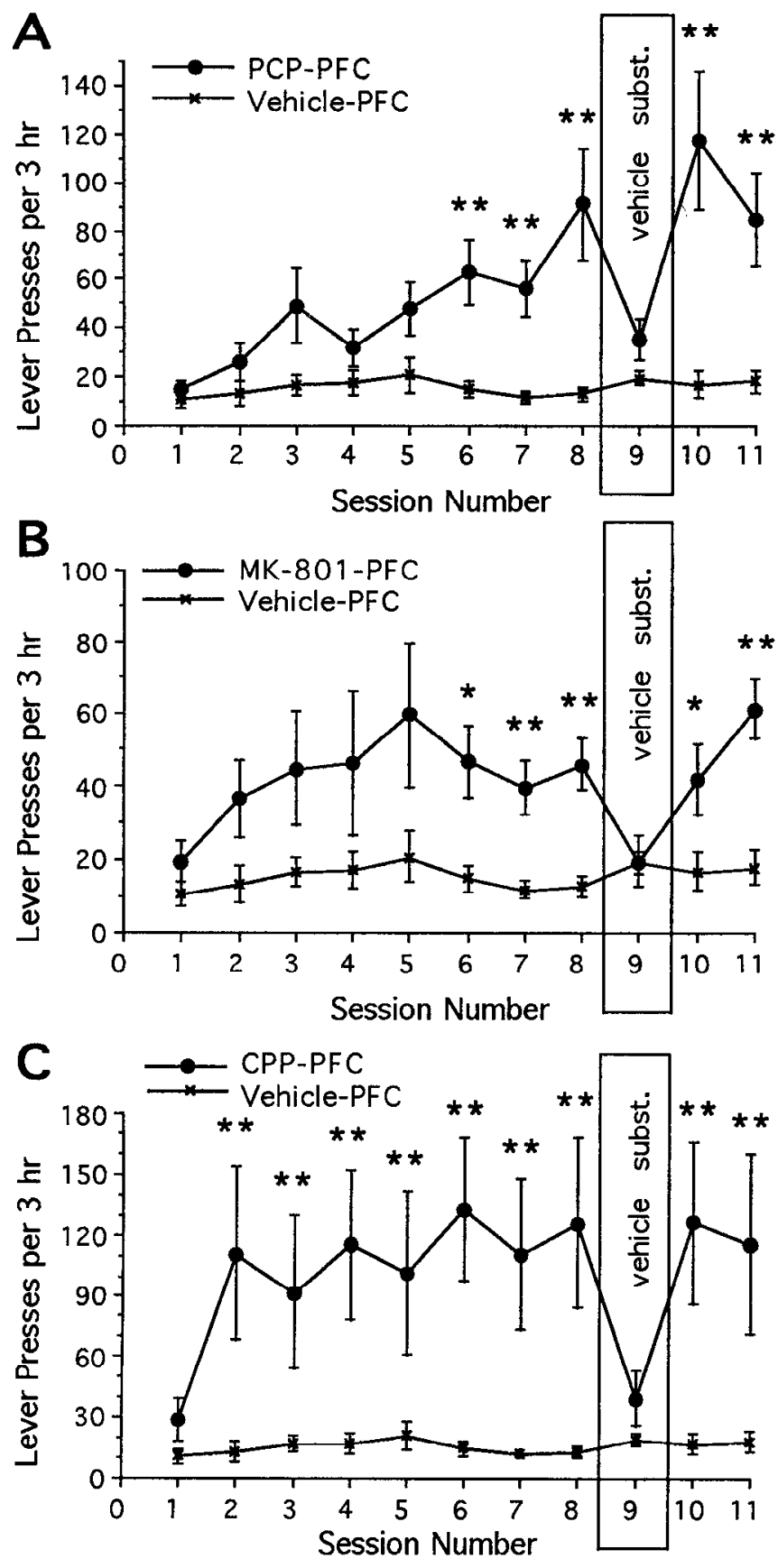

Figure 9. Mean \pm SEM number of lever-presses as a function of session for rats given access to microinjections of an NMDA receptor antagonist or vehicle directly into the frontal cortex. The number of lever-presses was increased for rats given response-contingent $\mathrm{PCP}(A)$ (interaction: $F_{(10,140)}$ $=3.88 ; p<0.0001$ ), MK-801 $(B)$ (main effect of sessions: $F_{(1,14)}=8.28$; $p<0.02$ ), or CPP $(C)$ (interaction: $F_{(101401}=1.91 ; p<0.05$ ) into the frontal cortex. Significant differences in the mean number of infusions between animals that received one of the NMDA receptor antagonists and animals that received vehicle for each daily session are depicted as follows (Tukey's tests): ${ }^{*} p<0.05,{ }^{* *} p<0.01$.

tively than they activate the sites tested here. Second, even if nucleus accumbens and frontal cortex prove to be the primary, or the only, sites of the rewarding action of PCP, it seems likely that it is an action at NMDA receptors rather than at the dopamine uptake carrier that explains the intracranial self-administration of the drugs tested here. Sulpiride, at a dose sufficient to block intracranial self-administration of the dopamine uptake inhibitor nomifensine, failed to block the rewarding effects of PCP, MK801, or CPP in nucleus accumbens. Third, MK-801 and CPP have actions at NMDA receptors but are not known to block dopamine uptake. Because PCP blocks NMDA receptors at concentrations lower than those that are needed to block dopamine uptake (Chaudieu et al., 1989; Ohmori et al., 1992), it seems reasonable to conclude tentatively that the rewarding effects of PCP are produced at doses below those needed to block dopamine uptake significantly.

For those familiar with the regularity of intravenous drug selfadministration, the variability of the present data may be troubling. The error bars are large, as are the variations from day to day and between replications. This is a reliable difference between intracranial and intravenous drug self-administration. Intracranial drug self-administration is not as regular as intravenous selfadministration. A number of factors may contribute. First, differences in injection site may account for differences in drug intake between animals. Second, it is quite possible that the drug is dispersed more readily from the circulatory system than from a central, single-point injection. Third, the present data are acquisition data, from the first week of self-administration; the regularity of intravenous self-administration usually is demonstrated in animals with several weeks of self-administration experience. Whatever the source of the variability, hourly drug intake is not regulated in intracranial self-administration to the extent that it is in intravenous self-administration.

The conclusion that co-infusion of sulpiride blocked or significantly attenuated the rewarding actions of intranucleus accumbens microinjections of nomifensine is based on three observations. First, the performance of animals tested repeatedly with the combination of nomifensine plus sulpiride during the substitution sessions was similar in progressive pattern to the performance of animals tested repeatedly with vehicle: response rates become progressively less vigorous across days of repeated testing. It is likely that the animals responded at near-normal levels during the first substitution session because well trained habits can perseverate for some timle even under conditions of nonreward. Continued responding under conditions of nonreward is characterized as "resistance to extinction" (Skinner, 1933), and such resistance decreases more and more quickly if animals are tested repeatedly under conditions of nonreward (Williams, 1938; Miles, 1956). Similarly, animals extinguish more and more quickly when the

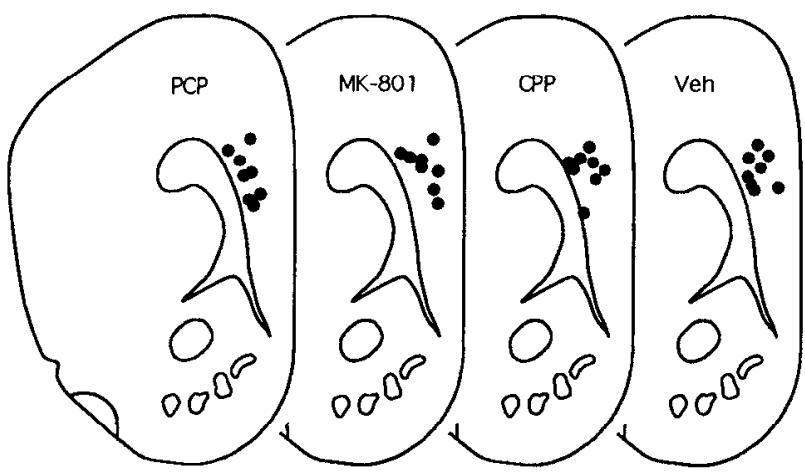

Figure 10. Cannula placements for response-contingent frontal cortex drug injections. All placements are represented on the same anteriorposterior section ( $4.2 \mathrm{~mm}$ anterior to bregma); actual placements varied between 3.9 and $4.5 \mathrm{~mm}$ anterior to bregma (figure adapted from Pellegrino et al., 1979). 
reward system is blocked repeatedly during some fraction of the test sessions (Wise et al., 1978; Mason et al., 1980) (Fig. 2), or if the reinforcer is rendered repeatedly irrelevant by satiating the animals just before some fraction of their testing sessions (Morgan, 1974). Decreased resistance to extinction across repeated extinction testing, with retraining under normal reinforcement between such testing, thus distinguishes extinction from other forms of performance decrease (Williams, 1938). Second, the patterns of decreased responding within each session similarly were progressive, both in the nomifensine plus sulpiride condition and in the vehicle substitution condition. Animals generally responded at high rates at the beginning of a substitution session but responded less vigorously toward the end of a session; this is another mark of the extinction of a response habit (Skinner, 1933). Third, there was evidence that experience with the nomifensine plus sulpiride combination "transferred" when animals were tested subsequently with vehicle for the first time during the reversal session. The response rates of animals with previous experience with the nomifensine plus sulpiride combination were significantly lower than those of animals that were given vehicle during the first substitution session but similar to those that had been given vehicle on four occasions. Likewise, when animals with vehicle experience were tested subsequently with the nomifensine plus sulpiride combination during the reversal session, their response rates were significantly lower than those of animals that were given the nomifensine plus sulpiride combination during the first substitution session but similar to those of animals that had been given the combination on four occasions. Thus the animals seemed to generalize from the nomifensine plus sulpiride condition (presumably a "reward blockade" condition) and the vehicle (nonreward) condition and vice versa. That is, 3 or $4 \mathrm{~d}$ of testing in one of these treatment conditions caused the same decrease in responding for subsequent tests as did 3 or $4 \mathrm{~d}$ of testing in the other condition, even when the treatment conditions were reversed for the subsequent test. The present findings are consistent with the findings of Goeders and Smith (1983), who reported that co-infusion of sulpiride decreased the rewarding effects of cocaine in the frontal cortex.

Co-infusion of the concentration of sulpiride that effectively blocked the rewarding effects of nucleus accumbens nomifensine seemed not to block the rewarding effects of nucleus accumbens PCP, MK-801, or CPP in animals trained to self-administer these NMDA receptor antagonists. Lever-pressing rates did not decrease, even with repeated testing, when sulpiride was co-infused with each of the NMDA receptor antagonists, although they did decrease when vehicle was substituted for each of the drugs. Furthermore, when animals accustomed to receiving co-infusions of drug plus sulpiride during the substitution tests subsequently received vehicle for the first time during the reversal test, their lever-pressing rates were not different from those of animals given vehicle during the first substitution test. This finding suggests that experience with the drug plus sulpiride combination did not "transfer" to the vehicle condition. When animals accustomed to receiving vehicle during the substitution sessions were tested subsequently with the drug plus sulpiride combination, their response rates were similar to those seen during baseline testing. Together, these findings suggest that co-infusion of sulpiride does not cause any strong change in the rewarding effects of the NMDA antagonists; thus it seems that the rewarding effects of the NMDA antagonists are not dopamine-dependent. It remains possible that the dose of sulpiride that was tested in the present study simply was inadequate to block the rewarding effects of the
NMDA receptor antagonists and that higher doses might have proven effective.

Although the ineffectiveness of sulpiride challenge simply could reflect an inadequate dose of sulpiride, this seems an unlikely explanation. First, the dose was sufficient to block completely the reinforcing effects of nomifensine. If the dopamine uplakeinhibiting action of PCP were contributing significantly to the rewarding effects of the drug, sulpiride at this dose should have had some degree of effectiveness. Second, MK-801 and CPP, drugs with no known effect on dopamine uptake, were selfadministered, and sulpiride failed to block the rewarding effects of these agents. Thus the NMDA receptor-blocking action of PCP would seem to be sufficient to account for the reinforcing efficacy of the drug in the present experiments. Finally, the fact that PCP blocks NMDA receptors at doses too low to block dopamine function (Chaudieu et al., 1989; Ohmori et al., 1992) suggests that the rewarding actions shared with MK-801 and CPP at NMDA receptors become relevant before any possible contribution of a rewarding action of PCP at the dopamine uptake carrier.

Because selective NMDA antagonists and dopamine uptake inhibitors can serve as reinforcers in the nucleus accumbens, and perhaps in the frontal cortex (Goeders and Sinith, 1983), it seems that both the dopaminergic input from the ventral tegmental area and the glutamatergic inputs from the frontal cortex should be seen as contributing to mesocorticolimbic reward circuitry. In the case of the nucleus accumbens, dopaminergic and glutamatergic neurons synapse on common medium spiny output neurons (Sesack and Pickel, 1992), which probably contain GABA and are thought to serve as the final common path of opiate and psychomotor stimulant reward (Koob and Bloom, 1988; Self and Nestler, 1995; Wise and Bozarth, 1987). Glutamate and dopamine are believed to have opposite actions on their nucleus accumbens target neurons. Glutamate is believed to excite these neurons, and dopamine is believed to inhibit them. The selective NMDA receptor antagonists MK-801 and CPP and the indirect dopamine agonists amphetamine (Hoebel et al., 1983) and nomifensine (Carlezon et al., 1995) should decrease, from this perspective, the activity of GABAergic neurons of the nucleus accumbens. In this view, the NMDA receptor antagonists would do so by blocking the excitatory effects of glutamate at NMDA receptors, and amphetamine and nomifensine would do so by increasing extracellular concentrations of dopamine. Indeed, the results of the present experiments are consistent with the speculation of Carlsson and Carlsson (1990) that dopamine agonists and NMDA receptor antagonists have independent yet similar actions in the nucleus accumbens, and they suggest that either action is sufficient for drug reward. Separate subpopulations of medium spiny ncurons project to different levels in the anatomical cascade of GABAergic efferents from the striatum, however (Alexander and Crutcher, 1990), and it is possible that different drugs affect the different output populations differentially.

It seems likely that the medial prefrontal cortex interacts with the nucleus accumbens circuitry of drug reward. There are glutamatergic projections from the frontal cortex to both the nucleus accumbens, terminating on medium spiny neurons, and the ventral tegmental area, terminating on dopaminergic neurons (Sesack and Pickel, 1992). It is not clear how local NMDA antagonists interact with these projections, but it has been shown that rewarding cocaine injections into medial prefrontal cortex cause elevations of nucleus accumbens dopamine. Thus it has been proposed that accumbens is an output stage for the medial prefrontal cortex circuitry of cocaine reward (Goeders and Smith, 
1993). In the view proposed here, NMDA antagonists in medial prefrontal cortex would be expected to inhibit the firing of medium spiny neurons in nucleus accumbens; however, this is only one of several possibilities that should be explored.

Whatever the mechanism of action and whatever the links of reward circuitry between frontal cortex and nucleus accumbens, the present data implicate these structures, already implicated in the rewarding effects of psychomotor stimulants (Roberts et al., 1977; Lyness et al., 1979; Goeders and Smith, 1983; Hoebel et al., 1983; Carlezon et al., 1995) and opiates (Olds, 1982; Goeders et al., 1984), in the rewarding effects of NMDA receptor antagonists. Moreover, the absence of signs of aversion in animals receiving these central injections of PCP and related compounds suggests that these brain structures do not play a role in any aversive effects of these drugs, and that anatomically separable actions of PCP account for the ambivalence of animals receiving this complex drug systemically.

\section{REFERENCES}

Alexander GE, Crutcher MD (1990) Functional architecture of basal ganglia circuits: neural substrates of parallel processing. Trends Neurosci 13:266-271.

Balster RL, Woolverton WL (1980) Continuous-access phencyclidine self-administration by Rhesus monkeys leading to physical dependence. Psychopharmacology 70:5-10.

Barr GA, Paredes W, Bridger WH (1985) Place conditioning with morphine and phencyclidine: dose dependent effects. Life Sci 36:363-368.

Bozarth MA, Wise RA (1980) Electrolytic microinfusion transducer system: an alternative method of intracranial drug application. J Neurosci Methods 2:273-275.

Bozarth MA, Wise RA (1981) Intracranial self-administration of morphine into the ventral tegmental area in rats. Life Sci 28:551-555.

Carboni E, Imperato A, Perezzani L, DiChiara G (1989) Amphetamine, cocaine, phencyclidine and nomifensine increase extracellular dopamine concentrations preferentially in the nuclcus accumbens of freely moving rats. Neuroscience 28:653-661.

Carlezon Jr WA, Wise RA (1993a) Morphine-induced potentiation of brain stimulation reward is enhanced by MK-801. Brain Res 620:339-342.

Carlezon Jr WA, Wise RA (1993b) Phencyclidine-induced potentiation of brain stimulation reward: acute effects are not altered by repeated administration. Psychopharmacology 111:402-408.

Carlezon Jr WA, Devine DP, Wise RA (1995) Habit-forming actions of nomifensine in nucleus accumbens. Psychopharmacology 122:194-197.

Carlsson M, Carlsson A (1990) Interactions between glutamatergic and monoaminergic systems within the basal ganglia: implications for schizophrenia and Parkinson's disease. Trends Neurosci 13:272-276.

Chaudieu I, Vignon J, Chicheportiche M, Kamenka J-M, Trouiller G, Chicheportiche R (1989) Role of the aromatic group in the inhibition of phencyclidine binding and dopamine uptake by PCP analogs. Pharmacol Biochem Behav 32:699-705.

Collins RJ, Weeks JR, Cooper MM, Good PI, Russell RR (1984) Prediction of abuse liability of drugs using intravenous self-administration by rats. Psychopharmacology 82:6-13.

Corbett D (1989) Possible abuse potential of the NMDA antagonist MK-801. Behav Brain Res 34:239-246.

Crider R (1986) Phencyclidine: changing abuse patterns. NIDA Res Monogr 61:163-173.

Criswell HE (1977) A simple chronic microinjection system for use with chemitrodes. Pharmacol Biochem Behav 6:237-238.

DiChiara G, Imperato A (1988) Drugs of abuse preferentially stimulate dopamine release in the mesolimbic system of freely moving rats. Proc Natl Acad Sci USA 85:5274-5278.

Freeman AS, Bunney BS (1984) The effects of phencyclidine and $\mathrm{N}$-allynormetazocine on mid-brain dopamine neuronal activity. Eur $\mathbf{J}$ Pharmacol 104:287-293.

French ED (1986) Effects of phencyclidine on ventral tegmental $A_{10}$ dopamine neurons in the rat. Neuropharmacology 25:241-248.

French ED, Ceci A (1990) Non-competitive $N$-methyl-D-aspartate antagonists are potent activators of ventral tegmental A10 dopamine neurons. Neurosci Lett 119:159-162.
Gerhardt GA, Pang K, Rose GM (1987) In vivo electrochemical demonstration of the presynaptic actions of phencyclidine in rat caudate nucleus. J Pharmacol Exp Ther 241:714-721.

Goeders NE, Smith JE (1983) Cortical dopaminergic involvement in cocaine reinforcement. Science 221:773-775.

Goeders NE, Smith JE (1986) Reinforcing properties of cocaine in the medial prefrontal cortex: primary action on presynaptic dopaminergic terminals. Pharmacol Biochem Behav 25:191-199.

Goeders NE, Smith JE (1993) Intracranial cocaine self-administration into the medial prefrontal cortex increases dopamine turnover in the nucleus accumbens. J Pharmacol Exp Ther 265:592-600.

Goeders NE, Lane JD, Smith JE (1984) Self-administration of methionine enkephalin into the nucleus accumbens. Pharmacol Biochem Behav 20:451-455.

Hernandez L, Auerbach S, Hoebel BG (1988) Phencyclidine (PCP) injected into the nucleus accumbens increases extracellular dopamine and serotonin as measured by microdialysis. Life Sci 42:1713-1723.

Hiramatsu M, Cho AK, Nabeshima T (1989) Comparison of the behavioral and biochemical effects of the NMDA receptor antagonists, MK801 and phencyclidine. Eur J Pharmacol 166:359-366.

Hoebel BG, Monaco AP, Hernandez L, Aulisi EF, Stanley BG, Lenard L. (1983) Self-injection of amphetamine directly into the brain. Psychopharmacology 81:158 163 .

Hondo H, Yonezawa Y, Nakahara T, Nakamura K, Hirano M, Uchimura $H$, Tashiro N (1994) Effect of phencyclidine on dopamine release in the rat prefrontal cortex: an in vivo microdialysis study. Brain Res 633:337-342

Imperato I, Scrocco MG, Bacchi S, Angelucci L (1990) NMDA receptors and in vivo dopamine release in the nucleus accumbens and caudatus. Eur J Pharmacol 187:555-556.

Iwamoto ET (1986) Place-aversion conditioned by phencyclidine in rats: development of tolerance and pharmacological antagonism. Alcohol Drug Res 6:265-276.

Koek W, Colpaert $\Gamma C$ (1990) Selective blockade of $N$-methyl-D-aspartate (NMDA)-induced convulsions by NMDA antagonists and putative glycine antagonists: relationship with phencyclidine-like behavioral effects. J Pharmacol Exp Ther 252:349-357.

Koob GF, Bloom FE (1988) Cellular and molecular mechanisms of drug dependence. Science 242:715-723.

Kornetsky C, Esposito RU (1979) Euphorigenic drugs: effects on the reward pathways of the brain. Fed Proc 38:2473-2476.

Lyness WH, Friedle NM, Moore KE (1979) Destruction of dopaminergic nerve terminals in nucleus accumbens: effect on d-amphetamine selfadministration. Pharmacol Biochem Behav 11:553-556.

Mason ST, Beninger RJ, Fibiger HC, Phillips AG (1980) Pimozideinduced suppression of responding: evidence against a block of food reward. Pharmacol Biochem Behav 12:917-923.

McCullough LD, Salamone JD (1992) Increases in extracellular dopamine levels and locomotor activity after direct infusion of phencyclidine into the nucleus accumbens. Brain Res 577:1-9.

Miles RC (1956) Secondary-reinforcement stimulation throughout a series of spontaneous recoveries. J Comp Physiol Psychol 49:496-498.

Moghaddam B, Bunney BS (1989) Ionic composition of microdialysis perfusing solution alters the pharmacological responsiveness and basal outflow of striatal dopamine. J Neurochem 53:652-654.

Morgan MJ (1974) Resistance to satiation. Anim Behav 22:449-466.

Mundl WJ (1981) Constant-current source for an electrolytic microinfusion transducer system. J Neurosci Methods 4:287-290.

Ng Cheong Ton JM, Gerhardt GA, Friedemann M, Etgen A, Rose GM, Sharpless NS, Gardner EL (1988) The effects of $\Delta^{9}$-tetrahydrocannabinol on potassium-evoked release of dopamine in the rat caudate nucleus: an in vivo electrochemical and in vivo dialysis study. Brain Res 451:59-68.

Ohmori T, Koyama T, Nakamura F, Wang P, Yamashita I (1992) Effect of phencyclidinc on spontancous and $N$-methyl-D-aspartate (NMDA)induced efflux of dopamine from superfused slices of rat striatum. Neuropharmacology 31:461-467.

Olds ME (1982) Reinforcing effects of morphine in the nucleus accumbens. Brain Res 237:429-440.

Pavlov I (1928) Lectures on conditioned reflexes. New York: International Publishers.

Pellegrino LJ, Pellegrino AS, Cushman AJ (1979) A stereotaxic atlas of the rat brain, 2nd ed. New York: Plenum.

Pickens R, Harris WC (1968) Self-administration of d-amphetamine by rats. Psychopharmacology 12:158-163. 
Raja SN, Guyenet PG (1980) Effects of phencyclidine on the spontaneous activity of monoaminergic neurons. Eur J Pharmacol 63:229-233.

Roberts DCS, Corcoran ME, Fibiger HC (1977) On the role of ascending catecholaminergic systems in intravenous self-administration of cocaine. Pharmacol Biochem Behav 6:615-620.

Self DW, Nestler EJ (1995) Molecular mechanisms of drug reinforcement and addiction. Annu Rev Neurosci 18:463-495.

Sesack SR, Pickel VM (1992) Prefrontal cortical efferents in the rat synapse on unlabeled neuronal targets of catecholamine terminals in the nuclcus accumbens septi and on dopamine neurons in the ventral tegmental area. J Comp Neurol 320:145-160.

Skinner BF (1933) The rate of establishment of a discrimination. J Gen Psychol 9:302-350.

Thorndike EL (1898) Animal intelligence: an experimental study of the associative processes in animals. Psychol Monogr Gen Appl 8[Suppl 2]: $1-109$.

Thorndike EL (1933) A theory of the action of the after-effects of a connection upon it. Physiol Rev 40:434-439.

Wetzel MC (1963) Self-stimulation aftereffects and runway performance in the rat. J Comp Physiol Psychol 56:673-678.
Williams SB (1938) Resistance to extinction as a function of the number of reinforcements. J Exp Psychol 23:506-522.

Wise RA (1982) Common neural basis for brain stimulation reward, drug reward, and food reward. In: Neural basis of feeding and reward (Hoebel BG, Novin D, eds), pp 445-454. Brunswick, ME: Haer Institute.

Wise RA (1989) The brain and reward. In: The neuropharmacological basis of reward (Liebman JM, Cooper SJ, eds), pp 377-424. Oxford: Oxford UP.

Wise RA, Bozarth MA (1987) A psychomotor stimulant theory of addiction. Physiol Rev 94:469-492.

Wise RA, Hoffman DC (1992) Localization of drug reward mechanisms by intracranial injections. Synapse 10:247-263.

Wise RA, Spindler J, de Wit H, Gerber GJ (1978) Neuroleptic-induced "anhedonia" in rats: pimozide blocks the reward quality of food. Science 201:262-264.

Zahm DS, Brog JS (1992) On the significance of subterritories in the "accumbens" part of the ventral striatum. Neuroscience 50:751-767.

Zhang J, Chiodo LA, Freeman AS (1992) Flectrophysiological effects of MK-801 on rat nigrostriatal and mesoaccumbal dopaminergic neurons. Brain Res 590:153-163. 